\title{
O COMPORTAMENTO EMPREENDEDOR NA GERAÇÃO DA INOVAÇÃO NO SETOR DE LAVANDERIAS DOMÉSTICAS
}

Danilo Augusto De Souza Machado ${ }^{1}$

Rodrigo Lopes Nascimento ${ }^{1}$

Luiz Silva Dos Santos ${ }^{1}$

Leonel Cezar Rodrigues ${ }^{1}$

${ }^{1}$ Universidade Nove de Julho (UNINOVE) 


\section{O COMPORTAMENTO EMPREENDEDOR NA GERAÇÃO DA INOVAÇÃO NO SETOR DE LAVANDERIAS DOMÉSTICAS}

\section{Resumo}

O mercado de Pequenas e Médias Empresas (PMEs) no Brasil tem grande relevância econômica e expressiva responsabilidade no desenvolvimento econômico, segundo IBGE ressalta que exista aproximadamente seis milhões de (PMEs), corresponde a 97\% de todas as empresas existentes no país. Empregam 52\% de todos os trabalhadores urbanos do país, gerando 13 milhões de empregos com carteira assinada, para o sindicato do setor de lavanderias e (Sindlav) e a (ANEL) associação nacional de empresas de lavanderias afirmam que existam 9.500 lavanderias no país, sendo 7.400 do segmento doméstico, esse setor em específico vem se desenvolvendo no que tange às inovações tecnológicas, com empresas que até então usavam métodos arcaicos e gestão familiar: as pequenas e médias lavanderias domésticas estão se mostrando pré-dispostas a se modernizar e acompanhar a evolução tecnológica. Este trabalho tem como objetivo medir se o comportamento empreendedor gera inovação nas lavanderias domésticas. Para isso, tomou-se como base o Modelo Radar da Inovação Sawhney, Wolcott e Arroniz (2006) e o modelo do comportamento empreendedor Sebrae Empretec ( 2011) para medir a associação entre comportamento empreendedor e Inovação, caracterizando-se como um estudo quantitativo exploratório. O instrumento de pesquisa foi validado, e aplicado em um evento que reuniu empresários desse setor. Para as análises utilizaram-se técnicas estatísticas de análise de medidas de dispersão e centralidade, univariadas e multivariada. A amostra obtida por conveniência foi de 177 (cento e setenta e sete) empresários proprietários de pequenas e médias lavanderias domésticas. Os principais resultados mostram forte associação entre comportamento empreendedor e inovação, se conclui aderente às dimensões com resultados se relacionam e como contribuição se identifica que o comportamento empreendedor gera inovação nas lavanderias domésticas. Palavraschave: Comportamento Empreendedor, Geração de Inovação, Lavanderias Domésticas.

\section{Introdução}

Atualmente, as pequenas e médias empresas estão presentes nos mais variados setores, do comércio ao serviço. Um dos ramos, cuja procura aumenta no inverno e durante o período de chuvas, que se enquadra, em regra, como pequena ou média empresa, é a o setor de lavanderias. Segundo dados divulgados pelo Sindicato das Lavanderias (Sindilav) e pela Associação Nacional de Empresas de Lavanderias (ANEL) existem 9.500 lavanderias no país, sendo 7.400 do segmento doméstico e 2.100 do industrial. O setor doméstico, em específico, vem se desenvolvendo gradativamente no que tange às inovações tecnológicas visando aumentar sua competitividade agregando comodidade para o seus clientes. Até poucos anos

\section{Organizadores:}

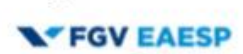

\section{Contmo of}

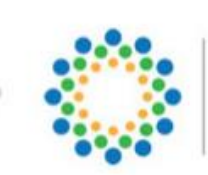

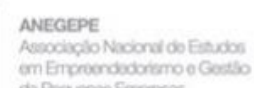
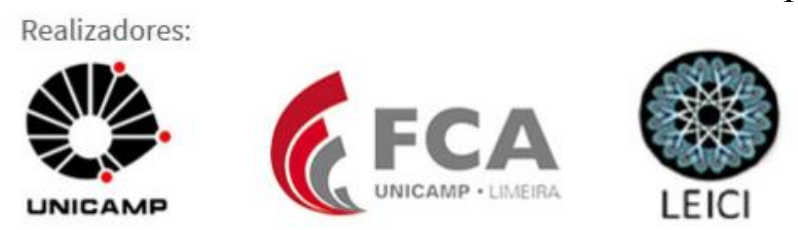
atrás as lavanderias faziam uso de métodos arcaicos e gestão familiar não se atentando para as novas tecnologias os empreendedores do ramo se viram cristalizados no que tange a inovação.

As poucas lavanderias que resistiam possuíam equipamentos antigos e um atendimento fora dos atuais padrões exigidos pelos consumidores, com a chegada de novos entrantes e franquias com modelo de negócio enxuto com foco em processos e resultados esses empreendedores se viram forçados a inovar para não perece. Entretanto, hodiernamente, as pequenas e médias lavanderias domésticas estão se mostrando prédispostas a se modernizar e acompanhar a evolução tecnológica. Esse fato pode ser facilmente notado ao se visitar lavanderias situadas em bairros da cidade de São Paulo, onde se constata a utilização de novos equipamentos, conexão com a rede mundial de computadores, dentre outros ferramentais tecnológicos inovadores. Adaptar-se às exigências do mercado mediante a aquisição de capacidade competitiva de curto prazo, modernização de equipamentos e utilização de novos meios de contratação aparenta ser o caminho que essas novas lavanderias vem seguindo. Uma análise superficial realizada após a visita a algumas lavanderias de bairro aponta que o processo está sempre em mudança, talvez motivado pelo mercado. Este cenário, extraído através de uma mera observação, chamou a atenção, motivando o desenvolvimento deste trabalho. E, ao se analisar os artigos publicados, constatou-se a existência de pouca literatura atinente ao setor de lavanderias, constituindo-se em uma lacuna. Em um primeiro momento, constata-se que, provavelmente, o empreendedorismo e a inovação estão presentes neste setor, $\log$ o o referido trabalho traz a seguinte pergunta de pesquisa que o comportamento empreendedor gera inovação nas lavanderias domésticas? Possibilitando essa recente transformação, logo esses dois elementos possibilitam a aquisição de geração de valor, para esse ramo que, até pouco tempo atrás, aparentava que seria extinto, comprovando-se que a estratégia de empreendedorismo corporativo possibilita a revitalização, inovação das organizações, fonte de vantagem competitiva e meio para buscar a sucesso sustentável (Cooper, et. al. 2002). Como contribuição, no tocante ao aspecto descritivo exploratório, destaca-se a identificação do atual panorama do nível de empreendedorismo e grau de inovação das lavanderias e, no tocante ao acréscimo teórico, ressalta-se a ideia de que uma gestão dotada de um comportamento empreendedor em conjunto com uma atuação com nível elevado de inovação possibilita a aquisição de capacidade competitiva.

\section{Referencial Teórico}

Atualmente, as pequenas e médias empresas estão presentes nos mais variados setores, do comércio ao serviço. Um dos ramos, cuja procura aumenta no inverno e durante o período de chuvas, que se enquadra, em regra, como pequena ou média empresa, é a o setor de lavanderias. Segundo dados divulgados pelo Sindicato das Lavanderias (Sindilav) e pela Associação Nacional de Empresas de Lavanderias (ANEL) existem 9.500 lavanderias no país,

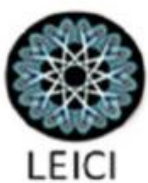


sendo 7.400 do segmento doméstico e 2.100 do industrial. O setor doméstico, em específico, vem se desenvolvendo gradativamente no que tange às inovações tecnológicas visando aumentar sua competitividade agregando comodidade para o seus clientes. Até poucos anos atrás as lavanderias faziam uso de métodos arcaicos e gestão familiar não se atentando para as novas tecnologias os empreendedores do ramo se viram cristalizados no que tange a inovação.

As poucas lavanderias que resistiam possuíam equipamentos antigos e um atendimento fora dos atuais padrões exigidos pelos consumidores, com a chegada de novos entrantes e franquias com modelo de negócio enxuto com foco em processos e resultados esses empreendedores se viram forçados a inovar para não perece. Entretanto, hodiernamente, as pequenas e médias lavanderias domésticas estão se mostrando prédispostas a se modernizar e acompanhar a evolução tecnológica. Esse fato pode ser facilmente notado ao se visitar lavanderias situadas em bairros da cidade de São Paulo, onde se constata a utilização de novos equipamentos, conexão com a rede mundial de computadores, dentre outros ferramentais tecnológicos inovadores. Adaptar-se às exigências do mercado mediante a aquisição de capacidade competitiva de curto prazo, modernização de equipamentos e utilização de novos meios de contratação aparenta ser o caminho que essas novas lavanderias vem seguindo. Uma análise superficial realizada após a visita a algumas lavanderias de bairro aponta que o processo está sempre em mudança, talvez motivado pelo mercado. Este cenário, extraído através de uma mera observação, chamou a atenção, motivando o desenvolvimento deste trabalho.

E, ao se analisar os artigos publicados, constatou-se a existência de pouca literatura atinente ao setor de lavanderias, constituindo-se em uma lacuna. Em um primeiro momento, constata-se que, provavelmente, o empreendedorismo e a inovação estão presentes neste setor, logo o referido trabalho traz a seguinte pergunta de pesquisa que o comportamento empreendedor gera inovação nas lavanderias domésticas? Possibilitando essa recente transformação, logo esses dois elementos possibilitam a aquisição de geração de valor, para esse ramo que, até pouco tempo atrás, aparentava que seria extinto, comprovando-se que a estratégia de empreendedorismo corporativo possibilita a revitalização, inovação das organizações, fonte de vantagem competitiva e meio para buscar a sucesso sustentável (Cooper, et. al. 2002). Como contribuição, no tocante ao aspecto descritivo exploratório, 
destaca-se a identificação do atual panorama do nível de empreendedorismo e grau de inovação das lavanderias e, no tocante ao acréscimo teórico, ressalta-se a ideia de que uma gestão dotada de um comportamento empreendedor em conjunto com uma atuação com nível elevado de inovação possibilita a aquisição de capacidade competitiva.

\section{Hipóteses}

Nesta seção serão testadas 04 (quatro) hipóteses de associações entre comportamento empreendedor e radar da inovação, com à perspectiva de identificar estatisticamente suas associações, a seguir:

H1- A independência e autoconfiança esta associada à criação de ofertas integradas e customizadas de produtos.

H2- A busca de oportunidade e iniciativa esta associado às novas formas de estruturar a empresa.

H3- O comprometimento esta associado à agregação de valor, ou seja, mecanismos pelos quais a empresa capta parte do valor criado.

H4- A persistência esta associada a o relacionamento com os consumidores, levando em consideração tudo que o cliente vê, ouve e sente na interação com a empresa.

\section{Método}

A escolha do método é importante para definir a estratégia de condução da investigação, bem como a classificação do trabalho científico quanto aos objetivos e procedimentos técnicos que serão utilizados. Nesse sentido, com o intuito de identificar o atual panorama do nível de inovação e grau de empreendedorismo das lavanderias localizadas no Estado de São Paulo, optou-se pela realização de uma pesquisa quantitativa, de caráter exploratório, a partir de dados primários adquiridos por meio de pesquisa de campo.

Entende-se que este tipo de pesquisa pode contribuir para um maior nível de entendimento em profundidade do comportamento empreendedor desse setor bem como suas particularidades e especificidades quanto à intenção de inovar e do comportamento individual. Por sua vez, a finalidade o referido trabalho tem cunho de caráter exploratório, segundo Andrade (1994), é inferir informações relevantes sobre determinado assunto, facilitando o entendimento do tema. Já Severino (2007) defende que a pesquisa de caráter exploratória possibilita demarcar o campo de trabalho que será realizado pela pesquisa, levantando

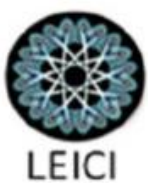


informações sobre um objeto específico, logo a referido trabalho visa responde o comportamento empreendedor gera inovação para o setor de lavanderias domésticas?

Tendo em vista as diretrizes estabelecidas, os dados foram obtidos por meio de pesquisa survey, guiado por questionário dividido em duas partes. A primeira parte teve como objetivo identificar o grau de empreendedorismo por meio da teoria das características do comportamento empreendedor (CCES). A segunda parte teve como objetivo identificar o nível de inovação por intermédio do instrumento radar da inovação para Sawhney et al. (2006), o instrumento propõe que a inovação seja tratada de forma holística, de modo que as organizações pondere sobre todas as dimensões onde seja possível inovar. Isso posta, a inovação deixa de estar vinculada à simples introdução de um produto ou processo novo na organização e torna-se a criação de um valor substancial para seus clientes. Foi utilizado o modelo Likert com 05 (cinco) níveis, onde o respondente declara uma das seguintes opções: 1-Nunca; 2-Raramente; 3-Algumas vezes; 4-A maioria das vezes e 5-Sempre pratico.

O instrumento de coleta de dados foi aplicado durante a realização de uma feira de negócios, que aconteceu na Cidade de São Paulo, localizada no Expo São Paulo Eventos, na feira LavTech, nos dias 21, 22 e 23 de agosto de 2017, onde se coletou uma amostra de 177 (cento e setenta e sete) respondentes. Ao ingressar no stand da feira o respondente era convidado a participar da pesquisa de forma livre e espontânea. Os dados obtidos foram tabulados em uma planilha do Microsoft Excel e as análises estatísticas de medidas de tendência central e os testes de associação (qui-quadrado) foram realizadas com o auxílio do software estatístico Ibm SPSS Statistics versão 20.

\section{Resultados}

O método de adotado neste levantamento é o de amostra conveniência, esta técnica de amostragem é muito comum e consiste em selecionar uma amostra da população que seja acessível, ou seja, os indivíduos empregados nesta pesquisa são selecionados porque eles estão prontamente disponíveis, não porque eles foram selecionados por meio de um critério estatístico. Geralmente essa conveniência representa uma maior facilidade operacional e baixo custo de amostragem, porém tem como conseqüência a incapacidade de fazer afirmações 
gerais com rigor estatístico sobre a população. A seguir serão apresentados os resultados descritivos e comparativos entre os sexos masculino e feminino para o conjunto da amostra.

As análises estatísticas foram realizadas através de técnicas descritivas, medidas de tendência central e distribuição de freqüências, para análises univariadas e tabulações cruzadas. Para as comparações entre gênero masculino e feminino nesta amostra coletada adotou-se um nível de significância de 5\% $(0,05)$ para um intervalo de confiança de $95 \%$ $(0,95)$. Foram analisadas as comparações de médias de idade, realizou-se testes não paramétricos, assumindo-se que a distribuição dos dados não obedeciam uma distribuição aderente a normalidade dos dados.

Foram realizadas 177 (cento e setenta e sete) entrevistas sendo 79 (46,5\%) do sexo masculino, com idade variando de 19 a 75 anos, com média de 46,3 e desvio padrão de 11,8 e para o sexo feminino 91 (53,5\%) com idade variando de 20 a 69 anos, com média de 43,8 e desvio padrão de 11,6 anos de vida. É possível verificar uma participação maior das mulheres e com média de idade inferior a dos homens nesse ramo de negócio conforme pode ser verificado nas tabelas 1 e 2 a seguir: 
Tabela 1 - Sexo do respondente

\begin{tabular}{ccc}
\hline Sexo & Freqüência & $\%$ \\
\hline Masculino & 79 & 46,5 \\
Feminino & 91 & 53,5 \\
\hline Total & $\mathbf{1 7 0}$ & $\mathbf{1 0 0 , 0}$ \\
\hline
\end{tabular}

Fonte: elaborada pelos autores

Tabela 2 - Idade do respondente

\begin{tabular}{ccccc}
\hline Sexo & Mínima & Máxima & Média & $\begin{array}{c}\text { Desvio } \\
\text { padrão }\end{array}$ \\
\hline Masculino & 19 & 75 & 46,2 & 11,8 \\
Feminino & 20 & 69 & 43,9 & 11,7 \\
\hline Total & $\mathbf{1 9}$ & $\mathbf{7 5}$ & $\mathbf{4 4 , 9}$ & $\mathbf{1 1 , 8}$ \\
\hline
\end{tabular}

Fonte: elaborada pelos autores

A seguir na tabela 3 são apresentadas as médias de comportamento empreendedor onde pode verificar que a Busca de oportunidade e iniciativa é o item com a maior média $(4,06 \%)$, seguido por Persistência (4,02\%), e Correr Risco Calculado (3,81\%), sendo os itens melhor avaliados. 
Tabela 3 - Dimensões para Comportamento Empreendedor

\begin{tabular}{lcccc}
\hline \multicolumn{1}{c}{ Dimensões para Empreender } & Média & Mínimo & Máximo & $\begin{array}{c}\text { Desvio } \\
\text { Padrão }\end{array}$ \\
\hline 01-Busca de oportunidade e iniciativa & 4,06 & 1,00 & 5,00 & 1,05 \\
02-Persistência & 4,02 & 1,00 & 5,00 & 1,13 \\
03-Comprometimento & 3,62 & 1,00 & 5,00 & 1,24 \\
04-Exigência de qualidade e efíciência & 3,87 & 1,00 & 5,00 & 1,07 \\
05-Correr riscos calculados & 3,81 & 1,00 & 5,00 & 1,24 \\
06-Estabelecimentos de metas & 3,38 & 1,00 & 5,00 & 1,38 \\
07-Busca de informações & 3,56 & 1,00 & 5,00 & 1,37 \\
08-Planejamento e monitoramento sistemático & 3,53 & 1,00 & 5,00 & 1,35 \\
09-Persuasão e rede de contatos & 3,50 & 1,00 & 5,00 & 1,37 \\
10-Independência e autoconfiança & 3,71 & 1,00 & 5,00 & 1,39 \\
\hline
\end{tabular}

Fonte: Adaptado Empretec Sebrae (2011).

Na tabela 4 são apresentadas as médias de dimensões da inovação de acordo com o instrumento de Sawhney, Wolcott \& Arroniz, (2006) onde pode verificar que o item Presença que são as formas de comercialização e/ou distribuição dos produtos, a fim de aproximar a empresa do cliente (3,66\%), seguido pelo Ambiência Inovadora ou seja o ambiente propício á inovação $(3,64 \%)$ e o item Agregação de Valor mecanismos pelos quais a empresa capta parte do valor criado $(3,63 \%)$, sendo os itens melhor avaliados. 
Tabela 4 - Dimensões para Inovar (Radar da Inovação)

\begin{tabular}{lcccc}
\hline \multicolumn{1}{c}{ Dimensões para Inovar } & Média & Mínimo & Máximo & $\begin{array}{c}\text { Desvio } \\
\text { Padrão }\end{array}$ \\
\hline 01- Oferta & 3,15 & 1,00 & 5,00 & 1,49 \\
02- Plataforma & 3,27 & 1,00 & 5,00 & 1,57 \\
03- Marca & 3,43 & 1,00 & 5,00 & 1,48 \\
04- Clientes & 3,44 & 1,00 & 5,00 & 1,28 \\
05-Soluções & 3,54 & 1,00 & 5,00 & 1,28 \\
06- Relacionamento (ou Experiência do & 3,40 & 1,00 & 5,00 & 1,35 \\
Consumidor) & & & & 1,00 \\
07- Agregação de valor (ou Captura de Valor) & 3,63 & 1,00 & 5,00 & 1,30 \\
08- Processos & 3,28 & 1,00 & 5,00 & 1,55 \\
09- Organização & 3,14 & 1,00 & 5,00 & 1,52 \\
10- Cadeias de Fornecimento & 3,18 & 1,00 & 5,00 & 1,46 \\
11- Presença & 3,66 & 1,00 & 5,00 & 1,37 \\
12- Rede (ou Relacionamentos) & 3,62 & 1,00 & 5,00 & 1,33 \\
13- Ambiência Inovadora & 3,64 & 1,00 & 5,00 & 1,44 \\
\hline
\end{tabular}

Fonte: Adaptado Sawhney, Wolcott \& Arroniz, (2006).

$\mathrm{Na}$ seguir a tabela 5 é apresentada as associações dos instrumentos, adotando o nível de significância de 5\% para o intervalo de confiança de $95 \%$, os itens Independência e Autoconfiança esta fortemente associada ao item Presença que visa explicar as formas de comercialização e/ou distribuição dos produtos, a fim de aproximar a empresa do cliente ( $\mathrm{p}$-value $=0,000)$, seguido do item Independência e auto Confiança esta associada ao item Organização onde são as novas formas de estruturar a empresa, de redesenhar o papel dos colaboradores e de redefinir parcerias (p-value $=0,001)$ e o item Comprometimento esta associado ao item Agregação de Valor onde é a adoção de novas formas de gerar receita por meio de produtos e processos já existentes ( $\mathrm{p}$-value $=0,007$ ), sendo os itens com maior associações significativas. 
Tabela 5 - Teste de associação entre as dimensões do comportamento

Empreendedor e de Inovação

\begin{tabular}{|c|c|c|c|}
\hline $\begin{array}{l}\text { Dimensão } \\
\text { Empreended } \\
\text { or }\end{array}$ & $\begin{array}{l}\text { Dimensão } \\
\text { Inovação }\end{array}$ & Chi-Square & $P$ valor \\
\hline CE-01 & CI-05 & 25.167 & $0,067^{* *}$ \\
\hline CE-02 & CI-06 & 28.295 & $0,029 *$ \\
\hline CE-03 & CI-02 & 26.461 & $0,048 *$ \\
\hline CE-03 & CI-03 & 24.220 & $0,085^{* *}$ \\
\hline CE-03 & CI-07 & 33.397 & $0,007 *$ \\
\hline CE-03 & CI-11 & 27.861 & $0.033 *$ \\
\hline CE-04 & CI-08 & 24.579 & $0,078^{* * *}$ \\
\hline CE-04 & CI-10 & 17.902 & $0,033 *$ \\
\hline CE-04 & CI-11 & 24.525 & $0,079^{* *}$ \\
\hline CE-07 & CI-01 & 24.094 & $0,087^{* *}$ \\
\hline CE-07- & CI-13 & 30.180 & $0,017 *$ \\
\hline CE-08 & CI-04 & 24.587 & $0,077 * *$ \\
\hline CE-08 & CI-05 & 26.073 & $0,053 *$ \\
\hline CE-10 & CI-04 & 24.904 & $0,072 * *$ \\
\hline CE-10 & CI-05 & $30 . .660$ & $0,015 *$ \\
\hline $\begin{array}{l}\text { Organizadores: } \\
\text { FGV EAESP }\end{array}$ & & & 1 \\
\hline
\end{tabular}


CE-10

CE-10

CE-10
CI-09

CI-11

CI-13
40.583

$0,001 *$

25.209

$0,066 * *$

42.218

$0,000 *$

* pvalor $<=0,05$ (Associação) $* *$ pvalor $>0,05$ e $<0,10$ (tendência) - Resultados da pesquisa

\section{Discussões}

Os resultados da pesquisa apresentaram no teste de hipótese H1a independência e autoconfiança esta associada à criação de ofertas integradas e customizadas de produtos, serviços e informação, utilizados para simplificar as dificuldades dos clientes, caracterizandose pelo amplo espectro de alternativas oferecidas, é confirmada pois se mostra estatisticamente relacionada e se mostra a corroborar a responder a pergunta de pesquisa haja visto que essa adaptação buscado a inovar para melhor atender sua demanda, esses empreendedores se mostram dispostos a desburocratizar seus processos em busca de resultados significativos economicamente.

Para $\mathrm{H} 2$ a busca de oportunidade e iniciativa esta associado às novas formas de estruturar a empresa, de redesenhar o papel dos colaboradores e de redefinir parcerias, não confirmada, ou seja, refutada estatisticamente, haja vista uma resistência forte ainda por parte desses empreendedores em modificar seu modelo de negócio, haja vista essa hipótese pode ser associada ao resultado de um setor conservador que busca se manter economicamente competitivos mas com ressalvas no que tange ao redesenho estrutural modificar as atividades dos seus colaboradores.

Entre tanto para H3 o comprometimento esta associado à agregação de valor, ou seja, mecanismos pelos quais a empresa capta parte do valor criado, foi confirmada, é estatisticamente associados e mostra que o setor esta comprometido a proporcionar valor aos seus clientes com base na inovação.

Para H4 a persistência esta associada a o relacionamento com os consumidores, levando em consideração tudo que o cliente vê, ouve e sente na interação com a empresa, foi confirmada, e é estatisticamente associada os empresários através do comportamento 
empreendedor esta antenada as novas tendências bem como compreende que seus clientes os avalia a todo instante e compara o valor entregue e julga o custo benefício e como isso é relevante na decisão do cliente retornar, essa persistência se mostra viável para compreender as mudanças e a satisfazer essa demanda.

Logo os resultados se mostra uma congruência e denota que comportamento empreendedor pode gerar inovação nas lavanderias domésticas e se propõem a responder a pergunta de pesquisa que por sua vez mostra a tentativa desses empresários de se posicionarem de forma contundente na tentativa de empreender e inovar para atender as necessidades do seu cliente. Em sintonia como comportamento empreendedor onde os resultados se mostram fortemente relacionados com a dimensão busca por iniciativa que enfoca a aceitação, a habilidade e a tendência para tomar iniciativas e a procurar e alcançar maior qualidade, produtividade, crescimento e lucratividade na atividade desenvolvida.

Envolve também a tendência de se colocar em situações moderadamente desafiadoras, conforme cada contexto e empreendedor, e de agir com determinação e compromisso na busca de resultados esperados, dessa forma, a inovação no contexto do comportamento empreendedor pode representar a criação de um produto, serviço ou processos que sejam considerados novos na unidade de negócio analisada, lo esse processo de inovação deve representar uma ação capaz de gerar valor à organização. É possível inovar na criação de novos produtos ou processos, na comercialização de produtos, no desenvolvimento de canais de distribuição ou em ações de marketing, entre outras ações que possam impactar no valor da empresa de forma sustentável e permanente. As ações de inovação tem impacto em múltiplas dimensões do Radar de Inovação. Independente da origem da inovação, seja no desenvolvimento de novos canais de comercialização ou na criação de um novo produto, haverá um impacto positivo nas dimensões analisadas em conjunto ao comportamento empreendedor entretanto é preciso destacar que a propagação desse impacto entre as dimensões que terá um impacto distinto, sobretudo de setores distintos. 


\section{Considerações Finais}

O trabalho apresenta em linhas gerais que o comportamento empreendedor pode gerar inovação nas lavanderias domésticas, bem como no que diz respeito às associações entre as ações inovadoras e comportamento empreendedor, verificou-se que há uma importante associação entre o desenvolvimento de diversas ações que conduzem a um ambiente inovador, no contexto das lavanderias domésticas. As inter-relações entre essas dimensões podem permitir um incremento dos resultados das atividades, à medida que determinadas ações podem potencializar os resultados satisfatórios, onde revele a contribuição do trabalho que aponta que o comportamento empreendedor gera inovação nas lavanderias domésticas.

A generalização dos resultados deste estudo fica comprometida, uma vez que a o método de amostragem foi por conveniência e exploratória para se identificar como o fenômeno se delineava. Sugere-se, dessa forma, a ampliação desta pesquisa contemplando uma amostra maior abrangendo um número maior de empreendedores e uma segmentação por tamanho do negócio.

Para estudos futuros se há uma lacuna em associar essas dimensões e se aprofundar com pesquisa qualitativa em profundidade e analisar esses fatores corroboram e influenciam o comportamento empreendedor. 


\section{REFERENCIAS}

Bachmann, D. L., \& DESTEFANI, J. H. (2008). Metodologia para estimar o grau de inovação nas MPE. XVIII Seminário Nacional de Parques Tecnológicos e Incubadoras de Empresas. Aracaju.

Besanko, D., Dranove, D., Shanley, M., \& Schaefer, S. (2009). Economics of strategy. John Wiley \& Sons.

Chesbrough, H. (2007). Business model innovation: it's not just about technology anymore. Strategy \& leadership, 35(6), 12-17.

Christensen, C. M. (2006). The ongoing process of building a theory of disruption. Journal of Product innovation management, 23(1), 39-55.

Cooper, A. C. (2002). Networks, alliances and entrepreneurship. Strategic entrepreneurship: Creating a new integrated mindset, 203-222.

Demográfico, IBGE Censo. Disponível em:< http://www. ibge. gov. br/home/estatistica/populacao/censo2016/default. shtm>. Acesso em, v. 30 de outubro de 2017.

Jorge Nassif, V. M., Bertoia Silva, N., Turuo Ono, A., Bontempo, P. C., \& Tinoco, T. (2010). Empreendedorismo: área em evolução? Uma revisão dos estudos e artigos publicados entre 2000 e 2008. RAI-Revista de Administração e Inovação, 7(1).

Lopes, R. M. A. (2010). Educação empreendedora: conceitos, modelos e práticas. Elsevier.

Nassif, V., Hashimoto, M., \& Amaral, D. J. (2014). Entrepreneurs Self-Perception of Planning Skills: Evidences from Brazilian Entrepreneurs.

Osterwalder, A., \& Pigneur, Y. (2010). Business model generation: a handbook for visionaries, game changers, and challengers. John Wiley \& Sons. 
Sarasvathy, S. D. (2001). Causation and effectuation: Toward a theoretical shift from economic inevitability to entrepreneurial contingency. Academy of management Review, 26(2), 243-263.

Sawhney, M., Wolcott, RC e Arroniz, I. (2006). As 12 formas diferentes para as empresas inovarem. MIT Sloan Management Review , 47 (3), 75.

Sarasvathy, S. D. (2001). Causation and effectuation: Toward a theoretical shift from economic inevitability to entrepreneurial contingency. Academy of management Review, 26(2), 243-263.

Sebrae. Referenciais Teóricos Empretec. Sebrae, 2011.

SERVIÇO BRASILEIRO DE APOIO ÀS MICRO E PEQUENAS EMPRESAS - SÃO PAULO. Lavanderias de sucesso. Disponível em: Acesso em: 30 de outubro de 2017.

SINDICATO, D. L. E. S. S. (2017). Disponível em www.sindlav.com.br acessado 21 de outubro de 2017.

Steyaert, C. (2007). 'Entrepreneuring'as a conceptual attractor? A review of process theories in 20 years of entrepreneurship studies. Entrepreneurship and regional development, 19(6), 453- 